\title{
Increase in decorin and biglycan in Duchenne Muscular Dystrophy: role of fibroblasts as cell source of these proteoglycans in the disease
}

\author{
Ricardo Fadic a, Valeria Mezzano b, Karin Alvarezb, Daniel Cabrerab, \\ Jenny Holmgren c, Enrique Brandan $b$ * \\ a Departamento de Neurología, Facultad de Medicina. Pontificia Universidad Católica de Chile, \\ Santiago, Chile \\ b Centro de Regulación Celular y Patología, Departamento de Biología Celular y Molecular, \\ Facultad de Ciencias Biológicas, MIFAB, Pontificia Universidad Católica de Chile, Santiago, Chile \\ c Instituto de Rehabilitación, Fundación Teletón, Santiago, Chile
}

Received: April 26, 2006; Accepted: June 23, 2006

\begin{abstract}
Fibrosis is a common pathological feature observed in muscles of patients with Duchenne muscular dystrophy (DMD). Biglycan and decorin are small chondroitin/dermatan sulfate proteoglycans in the muscle extracellular matrix (ECM) that belong to the family of structurally related proteoglycans called small leucine-rich repeat proteins. Decorin is considered an anti-fibrotic agent, preventing the process by blocking TGF- $\beta$ activity. There is no information about their expression in DMD patients. We found an increased amount of both proteoglycans in the ECM of skeletal muscle biopsies obtained from DMD patients. Both biglycan and decorin were augmented in the perimysium of muscle tissue, but only decorin increased in the endomysium as seen by immunohistochemical analyses. Fibroblasts were isolated from explants obtained from muscle of DMD patients and the incorporation of radioactive sulfate showed an increased synthesis of both decorin and biglycan in cultured fibroblasts compared to controls. The size of decorin and biglycan synthesized by DMD and control fibroblasts seems to be similar in size and anion charge. These findings show that decorin and biglycan are increased in DMD skeletal muscle and suggest that fibroblasts would be, at least, one source for these proteoglycans likely playing a role in the muscle response to dystrophic cell damage.
\end{abstract}

Keywords: Duchenne muscular dystrophy - proteoglycans - biglycan - decorin - interstitial fibrosis

\section{Introduction}

Duchenne Muscular Dystrophy (DMD) is a muscle degenerative disease, secondary to mutations in the

* Correspondence to: Dr. Enrique BRANDAN

Departamento de Biología Celular y Molecular, Facultad de Ciencias Biológicas, P. Universidad Católica de Chile, Casilla 114-D, Santiago, Chile.

Tel.: $56-2-6862725$

Fax: 56-2-6355395

E-mail: ebrandan@bio.puc.cl dystrophin gene, that remains invariably fatal in humans [1]. Since the discovery of the DMD gene about 20 years ago [2] the center of attention for therapeutic strategy has been focused towards the delivery of the missing gene/protein [3]. This has not yet been successful [4]. Increasing the understanding of the muscle cell response to the mutation may allow the design of alternative pharmacological therapies. In DMD the lack of dystrophin is followed by continuous 
cycles of degeneration and regeneration that result in extensive fibrosis and a progressive decrease of muscle mass. The muscle cell degeneration is thought to be secondary to a muscle cytoskeleton-extracellular matrix disruption [5]. This is presumed to lead to sarcolemmal instability which could render muscle fibers susceptible to necrosis [6]. The cause of fibrosis in DMD is not well understood. Dystrophin deficiency in the limbs of $m d x$ mice, animal models of DMD [7], does not necessarily result in muscle fibrosis. It is known that dystrophy associated fibrosis is characterized by the accumulation of extracellular matrix (ECM) material [8]. The interaction of growth factors and cytokines with the ECM affects their bioavailability and biological activity. On the other hand, proteins which form part of the ECM have signaling functions per se. The ECM, therefore, would most likely have an important function in muscle fibrosis. [9-11]. Proteoglycans are one of the main constituents of the ECM, and we have shown that their synthesis, including both heparan sulfate and chondroitin/dermatan (CS/DS) sulfate groups, is increased in $m d x$ mice [12]. Biglycan and decorin are two CS/DS proteoglycans of the small leucine-rich family of proteoglycans that belong to an expanding gene class whose distinctive feature is a structural motif, called the leucine-rich repeat. These proteoglycans are tissue organizers, orienting and ordering collagen fibrils during ontogeny and in pathological processes such as wound healing, tissue repair, and tumor stroma formation. Threedimensional modeling of their prototype protein core proposes a binding surface appropriate for interactions with ligand proteins such as soluble growth factors.

Besides its function as an ECM organizer, decorin, has the ability to bind cell surface receptors, it activates the epidermal growth factor receptor and is capable of forming complexes with various isoforms of TGF- $\beta$, thus modulating their activity [13]. The mRNA and protein levels of TGF- $\beta$, a known profibrotic cytokine, are significantly elevated in $m d x$ diaphragm [14]. Decorin is expressed during skeletal muscle differentiation [15] and its synthesis and expression are up-regulated during skeletal muscle differentiation in vitro [25]. It has a role during skeletal muscle terminal differentiation by activating TGF- $\beta$ dependent signaling pathways [16]. Biglycan is expressed in secondary myotubes during fetal muscle formation [15]. In adult muscle it is located in the endomysium and neuromuscular junctions, where it connects to the dystrophin-asso- ciated proteins through binding to $\alpha$-dystroglycan [17]. In developing newborn mice biglycan expression is initially high and then decreases during skeletal muscle differentiation and maturation. Remarkably, a transient and important up-regulation of biglycan was associated with newly formed myotubes during injury induced muscle regeneration in mice [18]. There is little information about the putative role of these proteoglycans in dystrophic muscle fibrosis. In other organs decorin and biglycan seem to have dissimilar functions regarding fibrosis. The expression of decorin mRNA was increased, but biglycan mRNA expression was not elevated in kidney tubular epithelial cells and peritubular interstitium in a model of tubulointerstitial fibrosis [19]. In vivo, overexpression of TGF- $\beta$ resulted in marked lung fibrosis, which was significantly reduced by concomitant overexpression of decorin. Biglycan, however, had no significant effect on lung fibrosis induced by TGF- $\beta$ [20]. In a muscle regeneration model, myostatin (which belongs to the TGF- $\beta$ family of growth factors) null mice present smaller areas of fibrotic tissue parallel to an increased expression of decorin mRNA [21]. Neutralization of TGF- $\beta 1$ by decorin administration resulted in a $40 \%$ reduction in the level of type I collagen mRNA in the diaphragm of dystrophic mice [14]. Biglycan may also have a role in the fibrotic process since it is overexpressed in atherosclerotic lesions and has been shown to cause an increase in thymidine incorporation and migration of vascular smooth muscle cells [22].

The only information available about decorin and biglycan levels in DMD comes from gene expression profiles of skeletal muscle biopsies that demonstrated increased amount of both proteoglycans [23]. Information regarding their cell source and as well as tissue localization is missing. We therefore decided to study both proteoglycans in DMD patients' muscle biopsies and cultured fibroblasts obtained from explants of DMD skeletal muscle tissue.

\section{Material and methods}

\section{Muscle samples}

Biopsies from individuals were obtained from quadriceps muscles during diagnostic or surgical procedures, 
in accordance with university ethical rules. DMD Patient 1 (D1): 8 year-old boy first evaluated for delay in walking at 19 months of age, and subsequently developing progressive muscle weakness. He had no relatives with myopathies. CPK was 20,000 IU/ml. Dystrophin was absent in his muscle biopsy. Patient 2 (D2): 4 year-old boy with muscle pains since the age of 2 and a half, developing progressive muscle weakness shortly after that. Family history was negative for muscle disease. CPK was $>18,000 \mathrm{IU} / \mathrm{ml}$. EMG showed myopatic motor units with increased recruitment and muscle biopsy revealed muscle dystrophy. Immune histochemistry for dystrophin showed absence of the three-dystrophin domains. Samples obtained from 2 patients ( $\mathrm{C} 1$ and $\mathrm{C} 2$ ) without muscle diseases, undergoing a surgical orthopedic procedure in the hip or femur, were considered as controls. After sampling the biopsies were snap frozen in isopentane and stored at $-80^{\circ} \mathrm{C}$ until processing. Muscle biopsies used for cell cultures were kept in phosphate buffered saline until processed. Informed consent was obtained from all patients. The Ethics Committee of the Hospital Clínico de la P. Universidad Católica de Chile approved the study.

\section{Isolation of skeletal muscle proteoglycans}

Protein extracts were prepared as previously described [24]. Briefly, the muscle sample was homogenized in $4 \mathrm{M}$ guanidine-HCL, $0.05 \mathrm{M}$ sodium acetate ( $\mathrm{pH}$ 5.8), and $1 \mathrm{mM}$ PMSF at $4{ }^{\circ} \mathrm{C}$ and maintained under agitation for $18 \mathrm{~h}$. The supernatant was equilibrated by dialysis with $8 \mathrm{M}$ urea, $0.2 \mathrm{M} \mathrm{NaCl}, 0.05 \mathrm{M}$ sodium acetate, and $0.5 \%$ Triton $\mathrm{X}-100$ to remove guanidine. Samples were concentrated by DEAE-Sephacel anionexchange chromatography, equilibrated and washed with the same urea buffer, and eluted with $1.0 \mathrm{M} \mathrm{NaCl}$. The extracts were finally equilibrated by dialysis with a buffer containing $100 \mathrm{mM}$ Tris- $\mathrm{HCl}, 50 \mathrm{mM} \mathrm{NaCl}$, $\mathrm{pH} 7.5$, before enzymatic treatment.

\section{SDS-PAGE analysis of skeletal muscle proteoglycans}

Appropriate samples were digested with chondroitinase $\mathrm{ABC}$ and then analyzed by SDS-PAGE followed by fluorography using a $3-15 \%$ acrylamide gradient gel as described [25].

\section{Western blot analysis}

For proteoglycan detection, samples containing equivalent amounts of proteins were incubated with chondroitinase $\mathrm{ABC}$ and then analyzed by SDS-PAGE using a $3-15 \%$ acrylamide gradient. Proteins were transferred by electrophoresis to nitrocellulose membranes, detected with anti-mouse biglycan LF-106 or anti-mouse decorin LF-136 polyclonal antibodies (kindly donated by Dr. L. Fisher, NIDR, NIH, Bethesda, MD) [26], secondary horseradish peroxidase conjugated antibodies and visualized by enhanced chemiluminescence.

\section{Immunohistochemistry}

Cryostat sections $(8 \mu \mathrm{m})$ from DMD patients and controls were fixed with cold ethanol/acetic acid solution (1:1), rinsed with phosphate-buffered saline (PBS; pH 7.4), and blocked with an $8 \%$ BSA in PBS solution. They were then treated with $2.5 \mathrm{mU}$ chondroitinase $\mathrm{ABC}$ for $2 \mathrm{hrs}$ at $37^{\circ} \mathrm{C}$, and incubated overnight at $4{ }^{\circ} \mathrm{C}$ with primary antibodies against biglycan LF-51 (in 1:300 dilution) and decorin LF136 (in 1:700 dilution). Sections were then washed and incubated with either anti-rabbit FITC or antimouse TRICT (1:100) for $1 \mathrm{hr}$ at room temperature. For nuclear staining, sections were incubated with 1 $\mu \mathrm{g} / \mathrm{ml}$ Hoechst 33258 in PBS for 10 minutes. After rinsing, sections were mounted with fluorescent mounting media (Dako Corporation, CA) under glass cover slips and photographed with a Nikon Eclipse microscope equipped for epifluorescence. Specificity of anti-decorin and anti-biglycan was verified by the absence of staining after preincubation with an over tenfold excess of the purified proteoglycans subjected to chondroitinase ABC digestion.

\section{Cell culture}

Skeletal muscle samples were obtained from muscle biopsies of one DMD and one control patient and processed immediately after extraction. Fibroblasts were isolated from muscle explants as described previously [27]. Briefly, muscle biopsies were minced into pieces smaller than $1 \mathrm{~mm}^{2}$, seeded onto $3.8 \mathrm{~cm}^{2}$ well plates and covered with $500 \mu \mathrm{L}$ of growth medium (Dulbecco's modified eagle medium F-12, $100 \mathrm{U} / \mathrm{ml}$ 
penicillin, $0.1 \mathrm{mg} / \mathrm{ml}$ streptomicin and $0,25 \mathrm{ug} / \mathrm{ml}$ anfotericin B, Invitrogen) supplemented with $50 \%(\mathrm{v} / \mathrm{v})$ fetal calf serum (Hyclone). Explants were kept at $37^{\circ} \mathrm{C}$, $5 \% \mathrm{CO}_{2}$ and $95 \%$ humidity. After 3-4 days fibroblasts migrated from the muscle explants. When the cells covered $70-90 \%$ of the well surface they were tripsinized and plated onto $21 \mathrm{~cm}^{2}$ petri dishes, growth medium was switched to $20 \%$ FCS. Cells were used in passage 4 for all experiments.

\section{Gel filtration chromatography and SDS-PAGE}

Cells grown in $21 \mathrm{~cm}^{2}$ petri dishes were labeled with $\left[{ }^{35} \mathrm{~S}\right]-\mathrm{H}_{2} \mathrm{SO}_{4} 200 \mu \mathrm{C} / \mathrm{ml}$, in serum free $\mathrm{F}-12 \mathrm{HAM}$ medium for $6 \mathrm{~h}$. Conditioned media from DMD and control fibroblast cultures, obtained after metabolic labeling, were fractionated through a DEAE-Sephacel column $(0.5 \mathrm{ml}$ resin) pre-equilibrated in $10 \mathrm{mM}$ Tris$\mathrm{HCl}, \mathrm{pH} 7.5,0.2 \mathrm{M} \mathrm{NaCl}, 0.1 \%$ Triton $\mathrm{X}-100$ and eluted with a linear $\mathrm{NaCl}$ gradient $(0.2-1.0 \mathrm{M})$ at a flow rate of $5 \mathrm{ml} / \mathrm{h}$. Fractions of $1.0 \mathrm{ml}$ were collected and radioactivity was determined. Pooled fractions containing radioactive proteoglycans were then chromatographed on an analytical Sepharose CL-4B column $(100 \times 1 \mathrm{~cm})$ equilibrated and eluted with $1 \%$ SDS, $0.1 \mathrm{M} \mathrm{NaCl}, 50 \mathrm{mM}$ Tris-HCl buffer, $\mathrm{pH}$ 8.0. Samples $(0.5 \mathrm{ml})$ were applied to the column together with prefractionated dextran blue and phenol to mark void and total volumes respectively. Columns were eluted at a flow rate of $5 \mathrm{ml} / \mathrm{h}$, effluent fractions of 0.8 $\mathrm{ml}$ were collected and aliquots counted for radioactivity. Selected fractions from the Sepharose CL-4B column were analyzed by SDS-PAGE [25].

\section{Results}

\section{Decorin is increased in Duchenne muscular dystrophy and localizes in the muscle perimysium and endomysium}

To evaluate decorin content in muscle samples from DMD patients and controls, western blot analysis with a specific anti-human decorin antibody (LF136) was performed in chondroitinase $\mathrm{ABC}$ digested samples. As seen in Fig. 1A decorin core protein (filled arrow) and its glycanated form (open arrow) are increased in dystrophic muscle. No signal was detected in control muscles (Fig. 1A) when films were exposed for the same period of time. Protein profiles of DMD patients and control samples after Ponceau S staining of the same immunoblotted muscle homogenates is also shown (Fig. 1B). Decorin is secreted into the ECM and is located in the muscle perimysium [28]. To evaluate histological localization of the increased decorin muscle biopsy sections were stained with specific antidecorin antibody. As seen in Fig. 2 decorin is increased both in the perimysium and endomysium as compared to control muscles. Nuclei are shown in blue. An increase in nuclei localized particularly in the perimysium can be observed and may correspond to inflammatory infiltration and fibroblasts. According to these results we conclude that decorin is increased in DMD muscle and localizes at the perimysium and endomysium.

\section{Biglycan content is increased in Duchenne muscular dystrophy and is located mainly in the perimysium}

A similar procedure was performed to evaluate biglycan content. Western blot detection of biglycan in Fig. 3A shows an increase of the protein in the DMD patients as compared to controls. This antibody does not recognize the glycanated form of biglycan. Fig 3B shows Ponceau S staining of the same samples. As shown in Fig. 4 biglycan differs from decorin regarding tissue localization. The increase of the former in DMD muscle sections is mainly at the perimysium (Fig 4B).

\section{Fibroblasts obtained from DMD skeletal muscle show an increase in the synthesis of chrondroitin/dermatan sulfate proteoglycans}

The above results show that both decorin and biglycan content is increased in Duchenne skeletal muscle. Muscle is composed mainly of skeletal muscle fibers and mononucleated cells such as fibroblasts and macrophages. We measured proteoglycan synthesis in cultured fibroblasts obtained from muscle biopsies to determine if this cell type is, at least in part, responsible for the observed increase in decorin and biglycan. Fibroblasts were isolated 


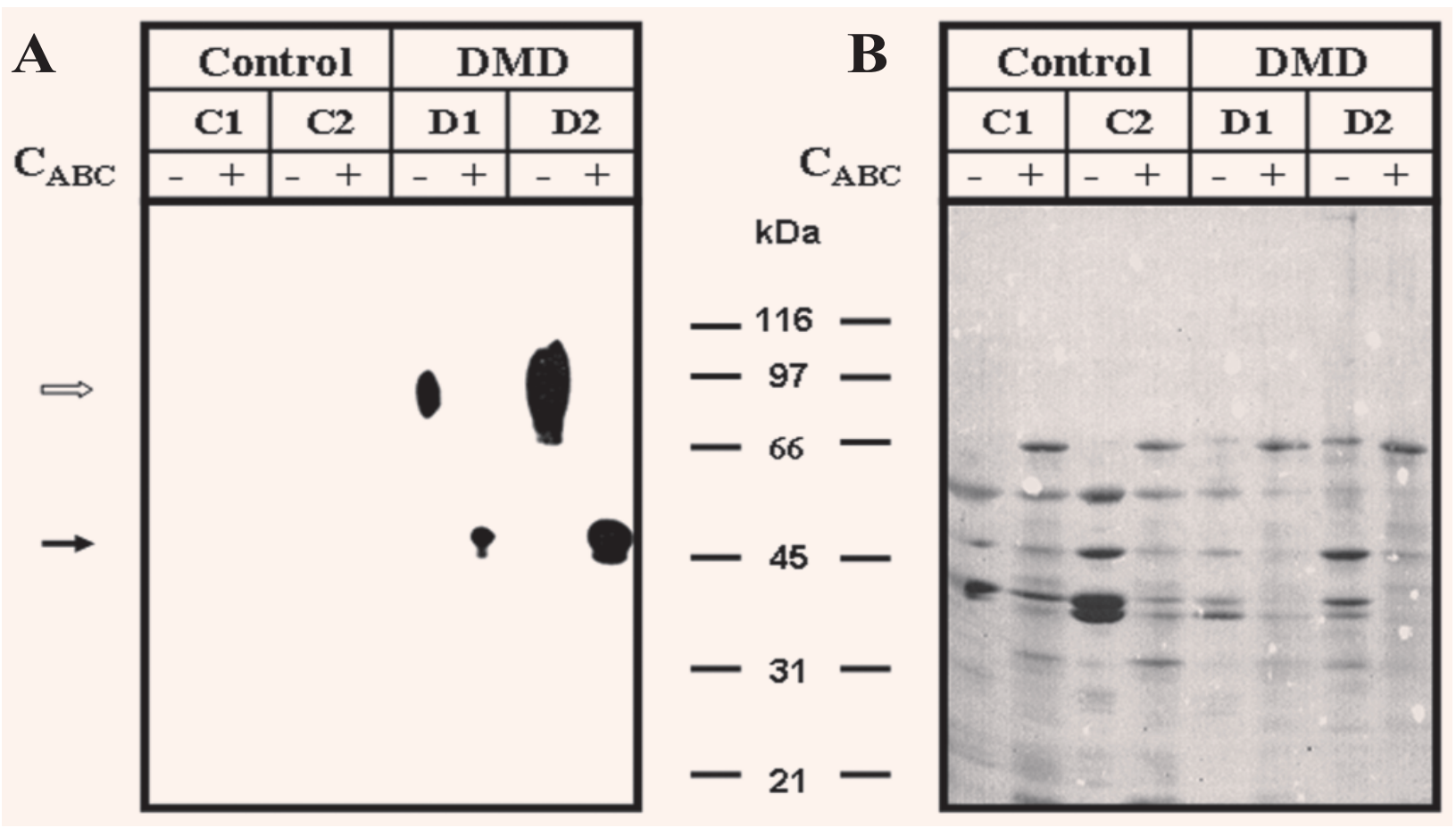

Fig. 1 Increases in the amount of decorin in DMD muscles. Western blot analyses were carried out using samples obtained from DMD and control biopsy extracts. $\mathrm{C} 1$ and $\mathrm{C} 2$ correspond to control biopsies and D1 and D2 to DMD patients. Fractions containing equivalent amounts of proteins were concentrated and incubated with and without chondroitinase $A B C\left(C_{A B C}\right)$, separated by SDS gel electrophoresis, transferred to nitrocellulose membranes, stained with specific antibodies against decorin to reveal decorin core protein using ECL. In (A), the open arrow shows decorin whereas the filled arrow corresponds to its core protein. In (B) the blot stained with Ponceau $\mathrm{S}$ is shown. Molecular weight standards are shown in the middle $(\mathrm{kDa})$.

CONTROL

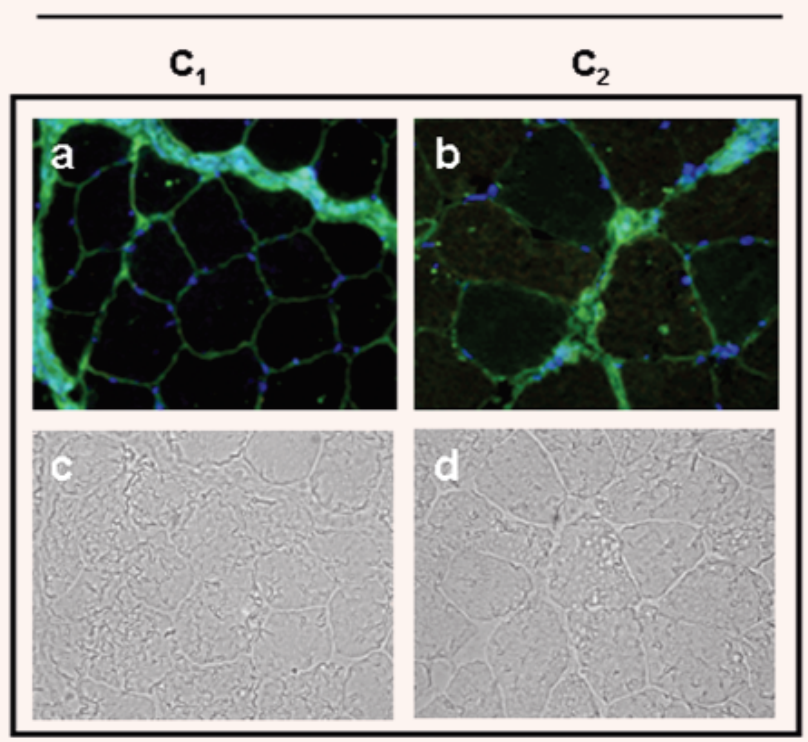

DMD

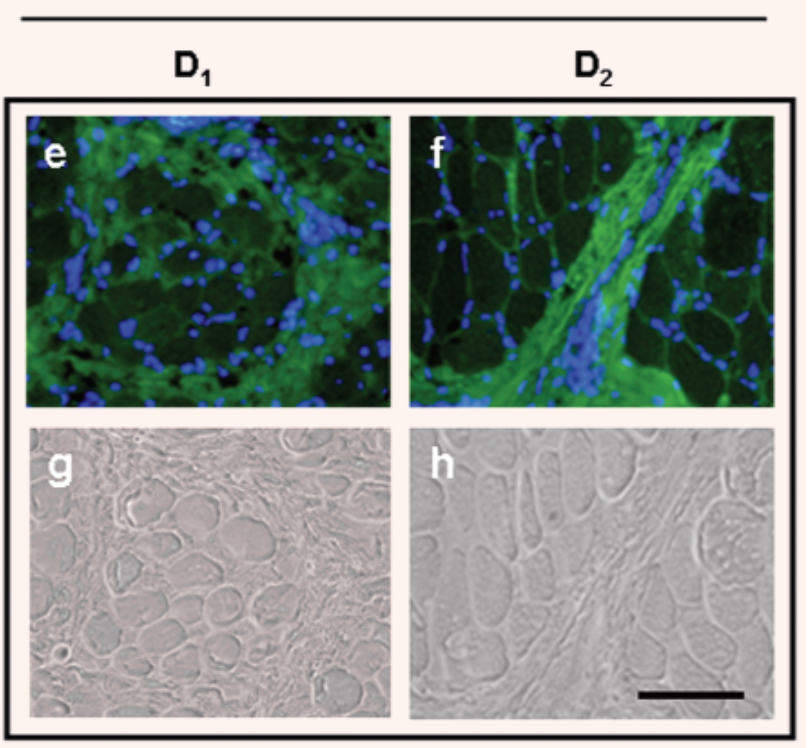

Fig. 2 Decorin increases in both endomysium and perimysium of DMD muscle. Indirect immunofluoresce performed in cross sections of DMD $\left(\mathrm{D}_{1}, \mathrm{D}_{2}\right)$ and control $\left(\mathrm{C}_{1}, \mathrm{C}_{2}\right)$ muscles shows decorin increase in the interstitium around each individual muscle fiber and in the space surrounding muscle fascicles. Nuclei are stained with Hoechst. Corresponding phase contrast photographs are shown underneath each section. Scale bar $=100 \mu \mathrm{m}$. 

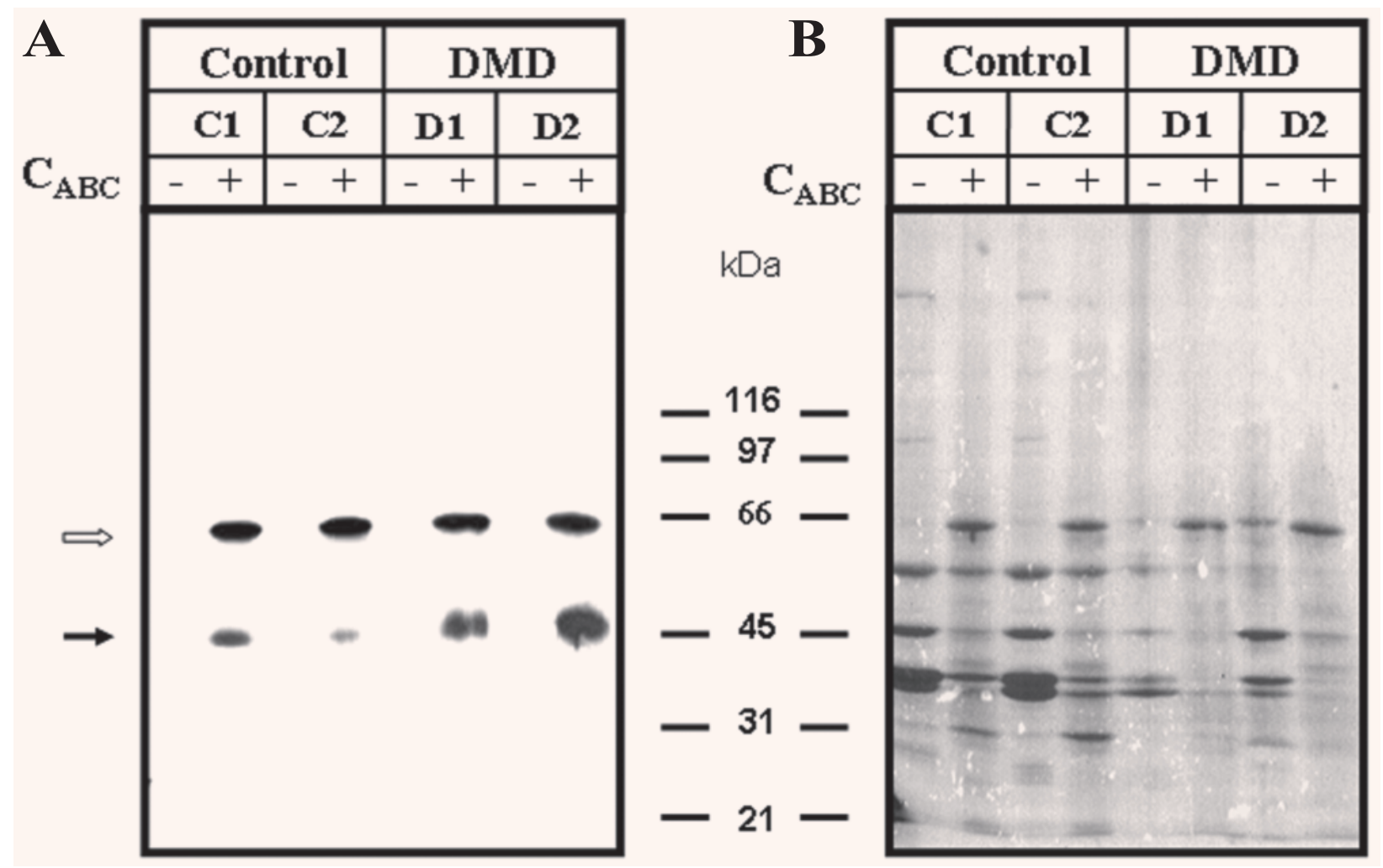

Fig. 3 Increases in the amount of biglycan in DMD muscles. Western blot analyses were carried out using soluble samples obtained from DMD biopsy extracts. C1 and C2 correspond to control biopsies and D1 and D2 to DMD patients. Fractions containing equivalent amounts of proteins were concentrated and incubated with and without chondroitinase $\mathrm{ABC}\left(\mathrm{C}_{\mathrm{ABC}}\right)$, separated by SDS gel electrophoresis, transferred to nitrocellulose membranes, stained with specific antibodies against biglycan to reveal biglycan core protein using ECL. In (A), the open arrow shows immunoreactivity to albumin present in the $\mathrm{C}_{\mathrm{ABC}}$ as preserving. The filled arrow corresponds to biglycan core protein. In (B) the blot stained with Ponceau $\mathrm{S}$ is shown. Molecular weight standards are shown in the middle (kDa).

from explants of DMD and control muscles as described in Material and Methods and incubated with radioactive sulfate for $6 \mathrm{~h}$. Incorporation of radioactive sulfate to macromolecules accumulated in the conditioned medium of cultured fibroblasts obtained from DMD and control skeletal muscles was determined by anion exchange chromatography. Fig. 5A shows a twofold increase in radioactive material obtained from DMD muscle fibroblasts (closed circles) compared to controls (open circle). In both situations radioactive molecules eluted from the columns at a salt concentration in the $0.6 \mathrm{M}$ range as described for chondroitin/dermatan sulfate proteoglycans $[24,28]$. The column profile was basically the same in fibroblasts from DMD and controls suggesting that there are no significant changes in glycosaminoglycan chain sulfation density. To determine if the size of proteogly- cans synthesized by DMD fibroblasts was different to controls, eluted fractions obtained from the DEAE-Sephacel columns containing the same amount of radioactive activity (c.p.m.), were fractionated through a Sepharose CL-4B column chromatography. Similar profiles, with a broad peak of Kav 0.2-0.6, were obtained from both DMD patients and controls (Fig. 5B). Digestion of these samples with chondroitinase $\mathrm{ABC}$ displaced almost all the radioactive material near Kav 1.0, indicating that the peak II obtained from the DEAE-Sephacel corresponds mainly to chondroitin/dermatan sulfate proteoglycans (Fig. 5C). To visualize the different radioactive soluble proteoglycans conditioned medium from fibroblast cell cultures were separated by SDS-PAGE and exposed to a radioactivity sensitive screen (Cyclone). Fig. 6 shows an increase of two [ $\left.{ }^{35} \mathrm{~S}\right]$-labeled species in DMD fibroblasts 


\section{CONTROL}

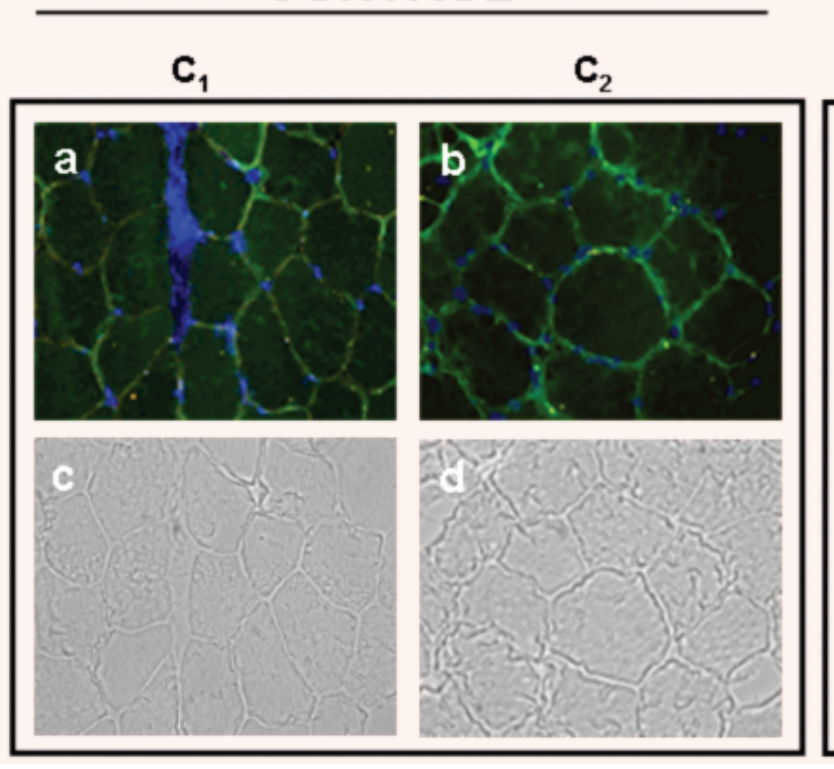

DMD

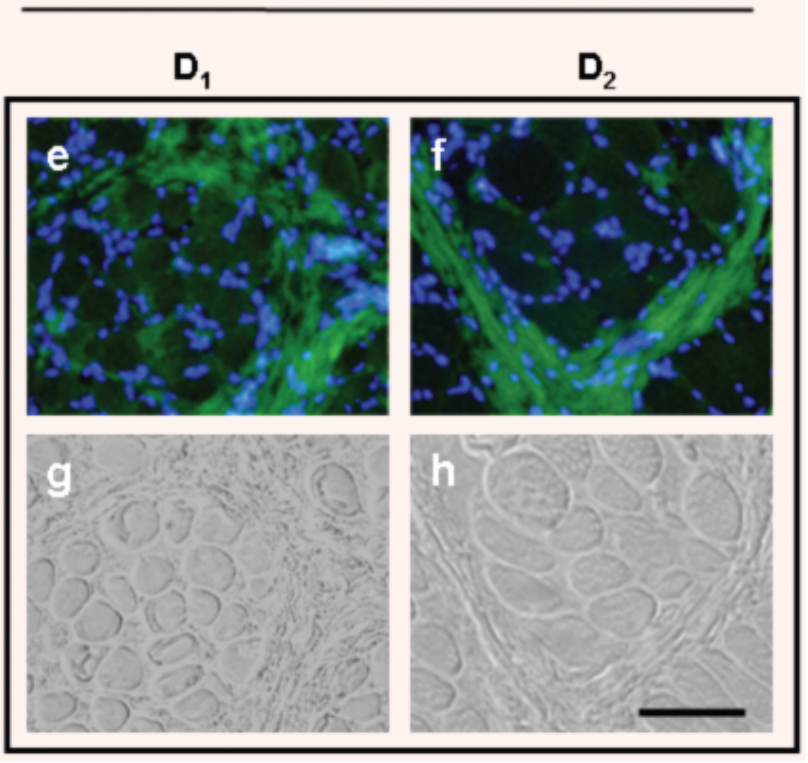

Fig. 4 Biglycan increases only in the perimysium of DMD muscle. Representative microphotograph of DMD (D1, $\mathrm{D} 2)$ and control $(\mathrm{C} 1, \mathrm{C} 2)$ muscle cross sections stained with antibodies against biglycan followed by a second FITCconjugated antibody. The biglycan signal increases in the interstitial space around muscle fascicles. Nuclei stained with Hoechst. Corresponding phase contrast photographs are shown below each section. The scale bar indicates $100 \mu \mathrm{m}$.
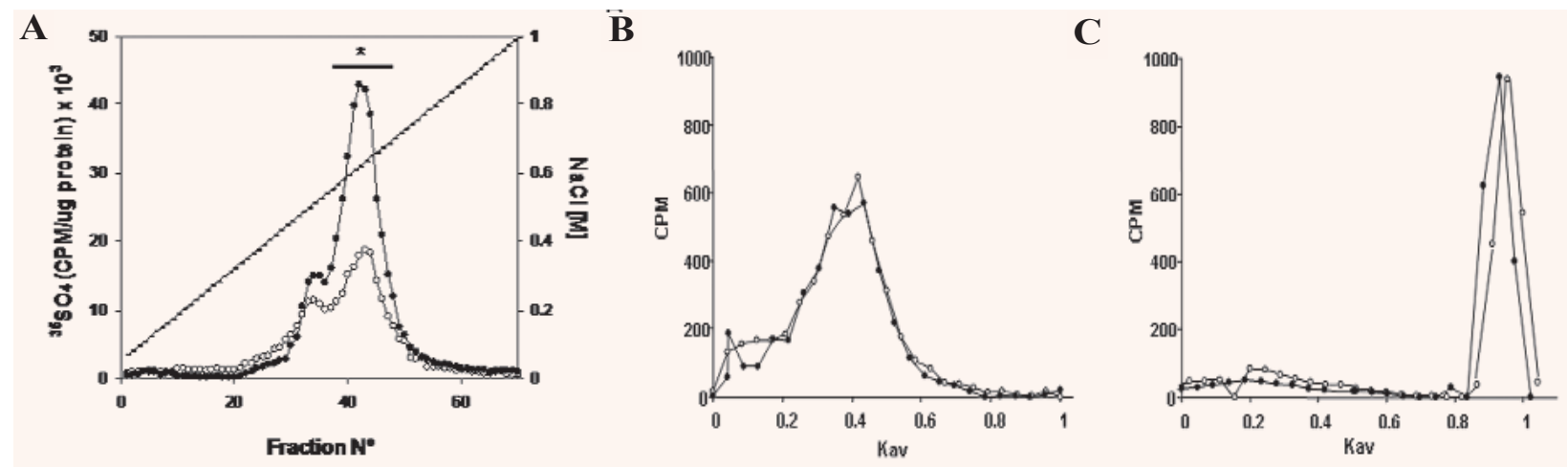

Fig. 5 Fibroblasts isolated from muscle DMD synthesize higher amounts of chondroitin/dermatan sulfate proteoglycans. A. The solid curves are DEAE-Sephacel profiles of conditioned medium corresponding to equal amounts of total cell extract proteins from DMD (solid circles) and control (open circles) isolated fibroblasts incubated with [ $\left.{ }^{35} \mathrm{~S}\right]-\mathrm{sul}-$ fate for $6 \mathrm{~h}$. The line indicates the $\mathrm{NaCl}$ gradient profile. The recovery from both columns was higher than $90 \%$. B. Conditioned medium from each DEAE column, indicated by a bar in A, were concentrated and chromatographed on a Sepharose CL-4B column. Samples loaded onto the column had equal amounts of cpm. $800 \mu$ fractions were collected and analyzed in a scintillation counter. C. Samples equivalent to B, were incubated with chondroitinase ABC previously to the chromatography on a Sepharose CL-4B column; almost all the radioactive material was displaced to the total volume of the column. The recovery from both columns ranged from 87 to $96 \%$.

(brackets). According to their known molecular weights and the sensitivity to chondroitinase $\mathrm{ABC}$ the upper band corresponds to biglycan and the lower to decorin (Fig. 6). Interestingly, radioactive material associated to the higher molecular weight heparan sulfate proteoglycans levels does not differ among fibroblasts from DMD skeletal muscle patients and controls (Fig. 6, asterisk). As a loading 
Fig. 6 Synthesis of decorin and biglycan is increased in DMD muscle isolated fibroblasts compared to control. Samples obtained from conditioned medium, corresponding to equal amounts of total cell extract proteins, of DMD and control fibroblasts were concentrated and subjected to SDS-PAGE followed by fluorography. On the left, upper and lower brackets indicate chondroitin/dermatan sulfate proteoglycans (biglycan and decorin, respectively). The asterisk corresponds to heparan sulfate proteoglycans. Sample treatments included: Heparitinase (Hase) and Chondroitinase $\mathrm{ABC} \quad\left(\mathrm{C}_{\mathrm{ABC}}\right)$. Molecular weight standards are shown $(\mathrm{kDa})$ in the middle. On the right, a coomassie staining of cell protein extracts shows equivalent amount of protein present in each sample.

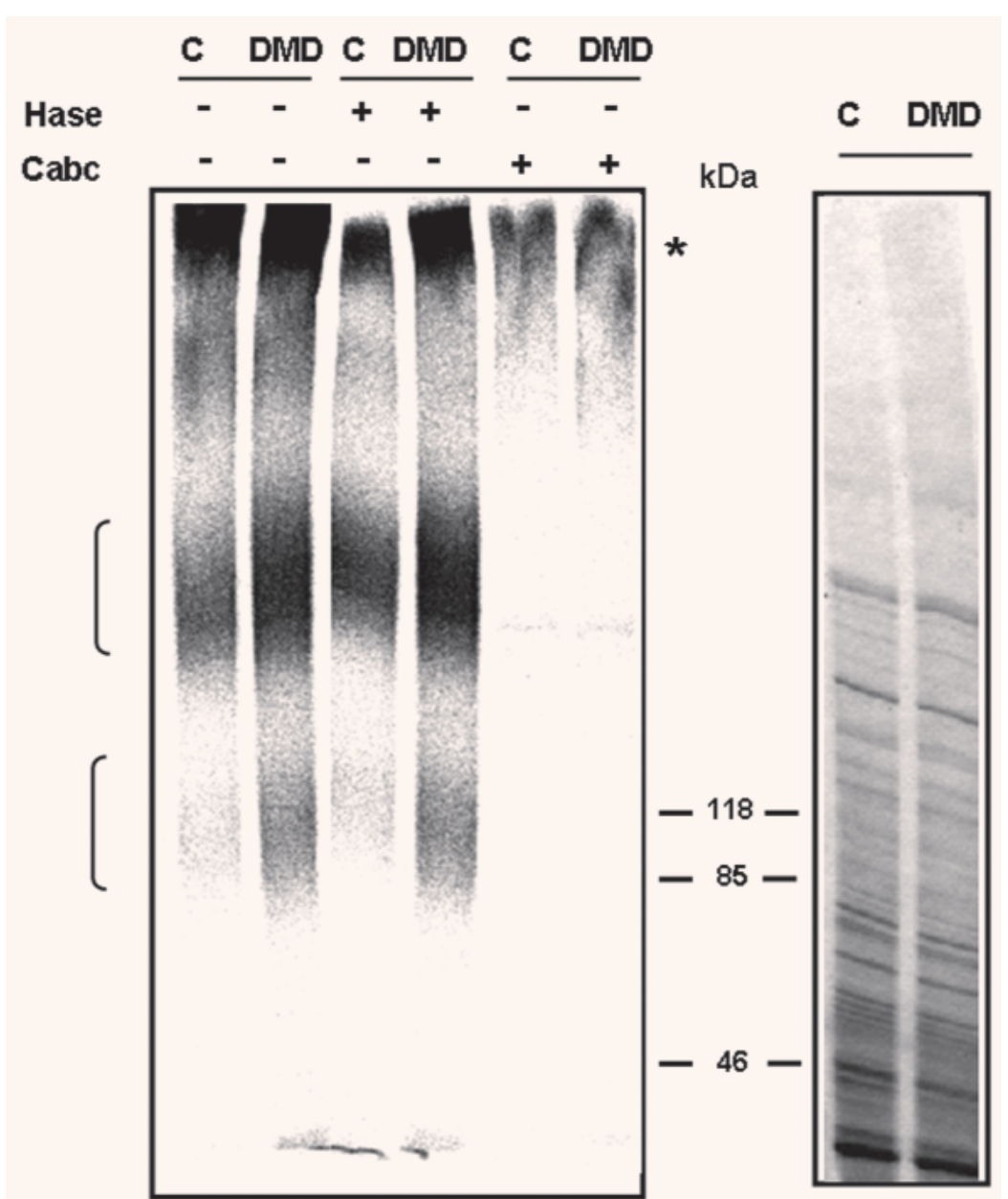

control coomassie staining of cell protein extracts equivalent to the percentage of analyzed conditioned media is shown on the right of Fig. 6 . Therefore, fibroblasts isolated from DMD muscle synthesize higher amounts of decorin and biglycan than fibroblasts isolated from control muscles.

\section{Discussion}

The histological phenotype of dystrophic muscle differs substantially from normal muscle. DMD skeletal muscle is characterized by necrosis and regeneration, fiber size variation, proliferation of connective and adipose tissue and infiltration of inflammatory cells. Even though the histology of DMD skeletal muscle is well described the causative molecular pathways are poorly understood.

Connective tissue infiltration is considered a secondary response that may further compromise muscle function in DMD. Biglycan and decorin are small extracellular proteoglycans that interact with cytokines and ECM proteins [13, 29]. They regulate the assembly of connective tissue and alter cell behavior during developmental and pathological processes. Decorin and biglycan have distinctive and differing distribution arrangements, with decorin being mainly related to collagen-rich connective tissues and biglycan restricted to the cell surface of certain cell types. Both decorin and biglycan are up-regulated in the ECM of $m d x$ mouse dystrophic muscle $[12,17]$ and have been shown to be increased in dystrophic muscle through microarray analysis [23]. Little is known about their expression in other muscular dystrophies. In $\alpha$ sarcoglycan deficiency (adhalin/ Limb girdle dystrophy 2D) a reduction of heparan sulfate proteoglycans in the basal lamina of the muscle fiber has been described, compared with other muscle diseases, however, no changes were seen in decorin in this condition [30]. A reduction of decorin expres- 
sion was reported in facioscapulohumeral muscular dystrophy myoblasts [31].

In this article we report an increase of both decorin and biglycan in skeletal muscle of DMD patients, and describe differences in their extracellular localization. We also show that cultured fibroblasts grown from DMD samples present an increased synthesis of decorin and biglycan but not heparan sulfate proteoglycans in the conditioned medium. This is the first report on the biochemical characteristics, localization and cell source of these species in DMD.

The role of both these molecules in DMD is not well understood. In other systems, decorin is considered to be a regulator of the scarring process. It has been postulated to have beneficial effects in atherogenesis reducing inflammation and fibrosis in atherosclerotic plaques of ApoE(-/-) mice [32]. It also regulates the proper healing response to myocardial infarctions as its absence leads to abnormal scar tissue formation in a heart infarction model [33]. Subconjunctival decorin applications significantly affect eye conjunctival scarring and surgical outcome of glaucoma filtration treatments in rabbits [34]. Decorin exerts beneficial effects on renal tubulointerstitial fibrosis, primarily by influencing the expression of a key cyclin-dependent kinase inhibitor and by limiting the degree of apoptosis, mononuclear cell infiltration, tubular atrophy, and expression of TGF- $\beta 1$ [35].

TGF- $\beta 1$ is a known profibrotic cytokine which is secreted by inflammatory cells among others. In this case we noted an increase in the amount of nuclei which may correspond to inflammatory cell infiltration.

In muscular dystrophies, TGF- $\beta 1$ plasma levels are significantly elevated in patients with DMD and congenital muscular dystrophy (CMD) [36]. TGF- $\beta 1$ mRNA levels in skeletal muscle from laminin alpha2negative and laminin alpha2-positive CMD patients are significantly greater than in controls. The TGF- $\beta 1$ values are lower than those found in DMD, although the extent of fibrosis is greater in CMD [37].

Decorin is able to sequester TGF- $\beta$ and thus decrease its bioavailability [38]. But it has also been reported that decorin antisense ODN-treated tendinocytes showed suppression of TGF- $\beta 1$ production [39]. Therefore, decorin increment in DMD muscle tissue might correspond to a cell effort to regulate fibrosis. Supporting this it has been shown that direct injection of decorin prevents TGF- $\beta 1$ induced scar tissue in vivo [40], and efficiently pre- vents fibrosis and enhances muscle regeneration in lacerated murine muscles [41, 42].

TGF- $\beta$ is able to inhibit myoblast differentiation in vitro [16], effect which can be attenuated by the addition of decorin. Interestingly, it has been reported that DMD myoblasts have a reduced proliferation rate together with a TGF- $\beta 1$ increase in conditioned media. This may be related to the DMD muscle diminished regeneration capacity [43]. Blocking TGF- $\beta 1$ could decrease fibrosis related to dystrophy since neutralization of TGF- $\beta 1$ by decorin administration resulted in a $40 \%$ reduction in the level of diaphragm muscle type I collagen mRNA [44].

Biglycan expression is also related to fibrotic processes, but not necessarily in parallel to decorin changes. Biglycan is overexpressed in atherosclerotic lesions, and it has been suggested to be involved in the regulation of vascular smooth muscle growth and migration through cdk2- and p27-dependent pathways. Furthermore, changes in biglycan expression could be a factor influencing the susceptibility of arteries to vascular injury [22]. In a bleomycininduced pulmonary fibrosis model, while decorin expression decreased, biglycan expression increased up to fourfold together with TGF- $\beta 1$. When active TGF- $\beta$ was overexpressed in vitro. Kolb found that both decorin and biglycan were able to interfere with TGF- $\beta$ bioactivity in a dose-dependant manner [20]. In vivo, adenoviral overexpression of TGF- $\beta$ resulted in marked lung fibrosis. This effect was significantly reduced by adenoviral mediated overexpression of decorin. When biglycan was overexpressed in the same manner, it had no significant effect on lung fibrosis. This data suggest that differences in tissue distribution, and/or cell source may be responsible for the different effects of biglycan on TGF- $\beta$ bioactivity in vivo [20].

We describe decorin and biglycan increments in different tissue compartments in DMD muscle at a stage in which fibrosis does not yet seem to be the main histological feature. We do not know if, as the disease progresses, there would be changes in the distribution of these molecules. Differential expression patterns, either spatial or temporal, of decorin and biglycan have been reported in other forms of fibrotic diseases. Biglycan has been mainly associated to the fibrous areas of the diseased tissue. Decorin has been observed to have a spatial distribution which varies with the stage of the disease, be it inflammatory or chronic fibrotic.[45-47]. In these 
biopsies biglycan was detected in the areas where connective tissue predominates and a fibrotic phenotype is being developed. Decorin on the other hand is seen surrounding the muscle fiber. This is an interesting observation if a protective role of decorin over the diseased fiber is argued. Furthermore, we have previously described an increase of decorin in the endomysium of $m d x$ mice leg muscles where muscular dystrophy is less severe and the tissue has a greater regenerative capacity.

The decorin and biglycan increase in DMD may also play a role in a remodeling attempt in response to injury. Biglycan and decorin induce morphological and cytoskeletal changes in fibroblasts, resulting in an increase in migration. [48]. This increase may have other functions, such as trophic ones. It has been described that biglycan synthesized by meningeal fibroblast cell cultures markedly enhances survival of rat neocortical neurons [49].

We found that fibroblasts isolated from DMD muscle biopsy samples have increased synthesis of decorin and biglycan. In the heart, after myocardial infarction, angiotensin II (AngII) promotes ventricular remodeling and deposition of ECM. When stimulated with AngII, neonatal cardiac fibroblasts produce biglycan as the predominant proteoglycan. Furthermore, neutralizing antibodies to TGF- $\beta 1$ inhibited biglycan induction in response to AngII [50]. In normal human skin and gingival fibroblast cultures TGF- $\beta 1$ markedly increased the expression of biglycan mRNAs, and the enhancement of biglycan expression was coordinated with elevated type I procollagen gene expression in the same cultures. In contrast, the expression of decorin mRNA was markedly inhibited by TGF- $\beta 1$ [51]. Our results also contrast with the increased amount of heparan sulfate proteoglycans found in whole muscle tissue in both DMD patients [52] and $m d x$ mice [12]. This suggests that the skeletal muscle fiber itself may be the source of increased heparan sulfate proteoglycans. It is known that perlecan and glypican, heparan sulfate proteoglycans, are synthesized by differentiated myotubes [53, 54]. However it must be noted that the proteoglycans analyzed here come from the conditioned medium of the cell cultures, it is also possible that heparan sulfate species are been associated to the cell and ECM.

In summary, both decorin and biglycan are increased in DMD muscle samples. They have distinct extracellular localization and, at least in part, this elevated amount is explained by an increased synthesis by fibroblasts. This phenomenon is similar to what we have described in the $m d x$ mouse. Further experiments are required to determine if this is a compensatory response to muscle or, on the contrary, indicate the beginning of fibrosis.

\section{Acknowledgements}

This work was supported in part by grants from FONDECYT 1020699 FONDAP-Biomedicine $\mathrm{N}^{\circ}$ 13980001, CONICYT AT-24050106 and MDA 3790. VM is supported by Catholic University School of Medicine (MECESUP Program). The research of E.B. was supported in part by an International Research Scholar grant from the Howard Hughes Medical Institute. The Millenium Institute for Fundamental and Applied Biology (MIFAB) is financed in part by the Ministerio de Planificación y Cooperación (Chile).

\section{Reference}

1. Bogdanovich S, Perkins KJ, Krag TO, Khurana TS. Therapeutics for Duchenne muscular dystrophy: current approaches and future directions. J Mol Med. 2004; 82: 102-15.

2. Monaco AP, Bertelson CJ, Middlesworth W, Colletti CA, Aldridge J, Fischbeck KH, Bartlett R, PericakVance MA, Roses AD, Kunkel LM. Detection of deletions spanning the Duchenne muscular dystrophy locus using a tightly linked DNA segment. Nature 1985; 316: 842-5.

3. van Deutekom JC, van Ommen GJ. Advances in Duchenne muscular dystrophy gene therapy. Nat Rev Genet. 2003; 4: 774-83.

4. Dubowitz V. Current and future therapy in muscular dystrophy; need for a common language between basic scientists and clinicians. Acta Myol. 2004; 23: V-IX.

5. Blake DJ. Dystrobrevin dynamics in muscle-cell signalling: a possible target for therapeutic intervention in Duchenne muscular dystrophy? Neuromuscul Disord. 2002; 12: S110-7.

6. Matsumura K, Tome FM, Collin H, Leturcq F, Jeanpierre M, Kaplan JC, Fardeau M, Campbell KP. Expression of dystrophin-associated proteins in dystrophin-positive muscle fibers (revertants) in Duchenne muscular dystrophy. Neuromuscul Disord. 1994; 4: 115-20.

7. Bulfield G, Siller W, Wight P, Moore K. X chromosomelinked muscular dystrophy (mdx) in the mouse. Proc Natl Acad Sci USA. 1984; 81: 1189-92. 
8. Rampoldi E, Meola G, Conti A, Velicogna M, Larizza L. A comparative analysis of collagen III, IV, laminin and fibronectin in Duchenne muscular dystrophy biopsies and cell cultures. Eur J Cell Biol. 1986; 42: 27-34.

9. Osses N, Brandan E. ECM is required for skeletal muscle differentiation independently of muscle regulatory factor expression. Am J Physiol Cell Physiol. 2002; 282: C383-94.

10. Larrain J, Carey DJ, Brandan E. Syndecan-1 expression inhibits myoblast differentiation through a basic fibroblast growth factor-dependent mechanism. $J$ Biol Chem. 1998; 273: 32288-96.

11. Fuentealba L, Carey DJ, Brandan E. Antisense inhibition of syndecan-3 expression during skeletal muscle differentiation accelerates myogenesis through a basic fibroblast growth factor-dependent mechanism. $J$ Biol Chem. 1999; 274: 37876-84

12. Caceres S, Cuellar C, Casar JC, Garrido J, Schaefer L, Kresse H, Brandan E. Synthesis of proteoglycans is augmented in dystrophic mdx mouse skeletal muscle. Eur J Cell Biol. 2000; 79: 173-81.

13. Iozzo RV. The biology of the small leucine-rich proteoglycans. Functional network of interactive proteins. $J$ Biol Chem. 1999; 274: 18843-6.

14. Gosselin LE, Williams JE, Deering M, Brazeau D, Koury S, Martinez DA. Localization and early time course of TGF-beta $1 \mathrm{mRNA}$ expression in dystrophic muscle. Muscle Nerve 2004; 30: 645-53.

15. Bianco P, Fisher LW, Young MF, Termine JD, Robey PG. Expression and localization of the two small proteoglycans biglycan and decorin in developing human skeletal and non-skeletal tissues. J Histochem Cytochem. 1990; 38: 1549-63.

16. Riquelme C, Larrain J, Schonherr E, Henriquez JP, Kresse H, Brandan E. Antisense inhibition of decorin expression in myoblasts decreases cell responsiveness to transforming growth factor beta and accelerates skeletal muscle differentiation. J Biol Chem. 2001; 276: 3589-96.

17. Bowe M, Mendis D, Fallon J. The small leucine-rich repeat proteoglycan biglycan binds to alpha-dystroglycan and is upregulated in dystrophic muscle. J Cell Biol. 2000; 148: 801-10.

18. Casar JC, McKechnie BA, Fallon JR, Young MF, Brandan E. Transient up-regulation of biglycan during skeletal muscle regeneration: delayed fiber growth along with decorin increase in biglycan-deficient mice. Dev Biol. 2004; 268: 358-71.

19. Suzuki K, Wang R, Kubota H, Shibuya H, Saegusa J, Sato T. Kinetics of biglycan, decorin and thrombospondin-1 in mercuric chloride-induced renal tubulointerstitial fibrosis. Exp Mol Pathol. 2005; 79: 68-73.

20. Kolb M, Margetts PJ, Sime PJ, Gauldie J. Proteoglycans decorin and biglycan differentially modulate TGF-beta- mediated fibrotic responses in the lung. $A m$ J Physiol Lung Cell Mol Physiol. 2001; 280: L1327-34.

21. McCroskery S, Thomas M, Platt L, Hennebry A, Nishimura T, McLeay L, Sharma M, Kambadur R. Improved muscle healing through enhanced regeneration and reduced fibrosis in myostatin-null mice. J Cell Sci. 2005; 118: 3531-41.
22. Shimizu-Hirota R, Sasamura H, Kuroda M, Kobayashi E, Hayashi M, Saruta T. Extracellular matrix glycoprotein biglycan enhances vascular smooth muscle cell proliferation and migration. Circ Res. 2004; 94: 1067-74.

23. Haslett JN, Sanoudou D, Kho AT, Bennett RR, Greenberg SA, Kohane IS, Beggs AH, Kunkel LM. Gene expression comparison of biopsies from Duchenne muscular dystrophy (DMD) and normal skeletal muscle. Proc Natl Acad Sci USA. 2002; 99: 15000-5.

24. Brandan E, Inestrosa NC. Isolation of the heparan sulfate proteoglycans from the extracellular matrix of rat skeletal muscle. J Neurobiol. 1987; 18: 271-82.

25. Brandan E, Fuentes ME, Andrade W. The proteoglycan decorin is synthesized and secreted by differentiated myotubes. Eur J Cell Biol. 1991; 55: 209-16.

26. Fisher LW, Stubbs JT $3^{\text {rd }}$, Young MF. Antisera and cDNA probes to human and certain animal model bone matrix noncollagenous proteins. Acta Orthop Scand Suppl. 1995; 266: 61-5.

27. Melone MA, Peluso G, Galderisi U, Petillo O, Cotrufo R. Increased expression of IGF-binding protein-5 in Duchenne muscular dystrophy (DMD) fibroblasts correlates with the fibroblast-induced downregulation of DMD myoblast growth: an in vitro analysis. $J$ Cell Physiol. 2000; 185: 143-53.

28. Brandan E, Fuentes ME, Andrade W. Decorin, a chondroitin/dermatan sulfate proteoglycan is under neural control in rat skeletal muscle. J Neurosci Res. 1992; 32: 51-9.

29. Kinsella MG, Bressler SL, Wight TN. The regulated synthesis of versican, decorin, and biglycan: extracellular matrix proteoglycans that influence cellular phenotype. Crit Rev Eukaryot Gene Expr. 2004; 14: 203-34.

30. Higuchi I, Fukunaga H, Matsumura K, Inose M, Izumi K, Okubo R, Nakagawa M, Shimizu T, Osame M. Abnormal expression of heparin sulfate proteoglycan on basal lamina of muscle fibers in two Japanese patients with adhalin deficiency. Neuromuscul Disord. 1995; 5: 467-74.

31. Winokur ST, Barrett K, Martin JH, Forrester JR, Simon M, Tawil R, Chung SA, Masny PS, Figlewicz DA. Facioscapulohumeral muscular dystrophy (FSHD) myoblasts demonstrate increased susceptibility to oxidative stress. Neuromuscul Disord. 2003; 13: 322-33.

32. Al Haj Zen A, Caligiuri G, Sainz J, Lemitre M, Demerens C, Lafont A. Decorin overexpression reduces atherosclerosis development in apolipoprotein E-deficient mice. Atherosclerosis 2005; In Press.

33. Weis SM, Zimmerman SD, Shah M, Covell JW, Omens JH, Ross J Jr, Dalton N, Jones Y, Reed CC, Iozzo RV, McCulloch AD. A role for decorin in the remodeling of myocardial infarction. Matrix Biol. 2005; 24: 313-24.

34. Grisanti S, Szurman P, Warga M, Kaczmarek R, Ziemssen F, Tatar O, Bartz-Schmidt KU. Decorin modulates wound healing in experimental glaucoma filtration surgery: a pilot study. Invest Ophthalmol Vis Sci. 2005; 46: 191-6.

35. Schaefer L, Macakova K, Raslik I, Micegova M, Grone HJ, Schonherr E, Robenek H, Echtermeyer FG, Grassel S, Bruckner P, Schaefer RM, Iozzo RV, Kresse H. Absence of decorin adversely influences tubulointersti- 
tial fibrosis of the obstructed kidney by enhanced apoptosis and increased inflammatory reaction. Am J Pathol. 2002; 160: 1181-91.

36. Ishitobi M, Haginoya K, Zhao Y, Ohnuma A, Minato J, Yanagisawa T, Tanabu M, Kikuchi M, Iinuma K. Elevated plasma levels of transforming growth factor beta1 in patients with muscular dystrophy. Neuroreport 2000; 11: 4033-5.

37. Bernasconi P, Di Blasi C, Mora M, Morandi L, Galbiati S, Confalonieri P, Cornelio F, Mantegazza $R$. Transforming growth factor-betal and fibrosis in congenital muscular dystrophies. Neuromuscul Disord. 1999; 9: 28-33.

38. Droguett R, Cabello-Verrugio C, Riquelme C, Brandan E. Extracellular proteoglycans modifies TGF-beta bioavailability attenuating its signaling during skeletal muscle differentiation. Matrix Biol. 2006; In Press.

39. Hosaka Y, Kirisawa R, Mafune N, Takehana K. Downregulation of decorin and transforming growth factor-betal by decorin gene suppression in tendinocytes. Connect Tissue Res. 2005; 46: 18-26.

40. Li Y, Foster W, Deasy BM, Chan Y, Prisk V, Tang Y, Cummins J, Huard J. Transforming growth factor-betal induces the differentiation of myogenic cells into fibrotic cells in injured skeletal muscle: a key event in muscle fibrogenesis. Am J Pathol. 2004; 164: 1007-19.

41. Fukushima K, Badlani N, Usas A, Riano F, Fu F, Huard J. The use of an antifibrosis agent to improve muscle recovery after laceration. Am J Sports Med. 2001; 29: 394-402.

42. Sato K, Li Y, Foster W, Fukushima K, Badlani N, Adachi N, Usas A, Fu FH, Huard J. Improvement of muscle healing through enhancement of muscle regeneration and prevention of fibrosis. Muscle Nerve 2003; 28: 365-72.

43. Melone MA, Peluso G, Petillo O, Galderisi U, Cotrufo R. Defective growth in vitro of Duchenne Muscular Dystrophy myoblasts: the molecular and biochemical basis. J Cell Biochem. 1999; 76: 118-32.

44. Gosselin LE, McCormick KM. Targeting the immune system to improve ventilatory function in muscular dystrophy. Med Sci Sports Exerc. 2004; 36: 44-51.

45. Hogemann B, Edel G, Schwarz K, Krech R, Kresse H. Expression of biglycan, decorin and proteoglycan100/CSF-1 in normal and fibrotic human liver. Pathol Res Pract. 1997; 193: 747-51.
46. Krull NB, Zimmermann T, Gressner AM. Spatial and temporal patterns of gene expression for the proteoglycans biglycan and decorin and for transforming growth factorbeta 1 revealed by in situ hybridization during experimentally induced liver fibrosis in the rat. Hepatology 1993; 18: 581-9.

47. Stokes MB, Holler S, Cui Y, Hudkins KL, Eitner F, Fogo A, Alpers CE. Expression of decorin, biglycan, and collagen type I in human renal fibrosing disease. Kidney Int. 2000; 57: 487-98.

48. Tufvesson E, Westergren-Thorsson G. Biglycan and decorin induce morphological and cytoskeletal changes involving signalling by the small GTPases RhoA and Rac1 resulting in lung fibroblast migration. J Cell Sci. 2003; 116: 4857-64.

49. Junghans U, Koops A, Westmeyer A, Kappler J, Meyer HE, Muller HW. Purification of a meningeal cell-derived chondroitin sulphate proteoglycan with neurotrophic activity for brain neurons and its identification as biglycan. Eur J Neurosci. 1995; 7: 2341-50.

50. Tiede K, Stoter K, Petrik C, Chen WB, Ungefroren H, Kruse ML, Stoll M, Unger T, Fischer JW. Angiotensin II AT(1)-receptor induces biglycan in neonatal cardiac fibroblasts via autocrine release of TGFbeta in vitro. Cardiovasc Res. 2003; 60: 538-46.

51. Kahari VM, Larjava H, Uitto J. Differential regulation of extracellular matrix proteoglycan (PG) gene expression. Transforming growth factor-beta 1 up-regulates biglycan (PGI), and versican (large fibroblast PG) but down-regulates decorin (PGII) mRNA levels in human fibroblasts in culture. J Biol Chem. 1991; 266: 10608-15.

52. Alvarez K, Fadic R, Brandan E. Augmented synthesis and differential localization of heparan sulfate proteoglycans in Duchenne muscular dystrophy. $J$ Cell Biochem. 2002; 85: 703-13.

53. Larrain J, Alvarez J, Hassell JR, Brandan E. Expression of perlecan, a proteoglycan that binds myogenic inhibitory basic fibroblast growth factor, is down regulated during skeletal muscle differentiation. Exp Cell Res. 1997; 234: 405-12.

54. Brandan E, Carey DJ, Larrain J, Melo F, Campos A. Synthesis and processing of glypican during differentiation of skeletal muscle cells. Eur J Cell Biol. 1996; 71: $170-6$. 